\title{
O PROCESSO DE OCUPAÇÃO URBANA E O SISTEMA DE ESPAÇOS LIVRES NA CONSTITUIÇÃO DA FORMA URBANA CONTEMPORÂNEA DE UMA CIDADE DE MÉDIO PORTE GAÚCHA
}

\section{THE PROCESS OF URBAN OCCUPATION AND THE SYSTEM OF OPEN SPACES IN THE CONSTITUTION OF THE CONTEMPORARY URBAN FORM OF A MEDIUM-SIZE CITY FROM RIO GRANDE DO SUL}

\author{
Laura Campagna Basso \\ Lauro André Ribeiro \\ Grace Tibério Cardoso
}

\section{Resumo}

Nas últimas décadas, as cidades brasileiras de porte médio têm conquistado uma maior importância e se consolidado. Passo Fundo se enquadra nesse cenário nacional, sendo atualmente reconhecida como uma cidade de médio porte e se apresentando como um importante centro regional do Rio Grande do Sul. Por isso, este artigo tem como objetivo principal apresentar a relação entre a ocupação urbana e o sistema de espaços livres intraquadra da cidade de Passo Fundo/RS, desenvolvendo seus aspectos metodológicos por meio de geoprocessamento e fotointerpretação de imagens.

Palavras-chave: Sistema de Espaços Livres. Forma urbana. Passo Fundo. Georreferenciamento.

\section{ABSTRACT}

In the last decades, Brazilian cities of medium size have become more important and consolidated. Passo Fundo fits into this national scenario, being now a medium-sized city and presenting itself as an important regional center of Rio Grande do Sul. Therefore, this article has as main objective to present a relationship between urban life and the system of free spaces in the city of Passo Fundo/RS, developing its methodological aspects through geoprocessing and photointerpretation of images.

Keywords: System of open spaces. Urban form. Passo Fundo. Georeferencing. 


\section{INTRODUÇÃo}

No Brasil, as cidades de porte médio têm conquistado uma maior importância e se consolidando a partir da década de 1970, quando os incentivos e investimentos em desenvolvimento urbano nacional se descentralizam das metrópoles. Esse aumento de interesse nas cidades médias se dá por diferentes aspectos - ambientais, econômicos, culturais - do desenvolvimento de cada cidade, de forma a proporcionar novas paisagens urbanas (COCOZZA et al., 2014). De acordo com Cocozza et al. (2014, p. 130), esses diferentes panoramas "devem ser estudados como integrantes das redes urbanas e detentores de características espaciais e ambientais próprias, na busca da qualidade urbana muitas vezes perdida nas metrópoles".

Estudos com o objetivo de compreender os processos que originaram a forma urbana de cidades brasileiras de médio e grande porte, tem sido realizados pela Rede Nacional de Pesquisa Quapá-SEL, formada por diversas instituições no Brasil, sendo o núcleo principal o Laboratório Quadro do Paisagismo no Brasil (LABQUAPÁ), da Faculdade de Arquitetura e Urbanismo de São Paulo (FAUUSP), São Paulo Capital (QUAPÁ, 2019). Além disso, estudos sobre os sistemas de espaços livres em pequenas cidades (MATÉ, 2016; MATÉ; SANTIAGO, 2017), também contribuem para a compreensão da forma urbana brasileira e destacam as diferenças existentes entre cidade de pequeno porte com os resultados já encontrados de cidades de maior porte. Tais referências são importantes componentes do estado da arte em estudos dessa temática no Brasil.

A cidade de Passo Fundo é reconhecida como uma cidade de porte médio no atual cenário nacional e se apresenta como um importante polo regional do Rio Grande do Sul. Tal afirmação é dada graças à sua caracterização quanto ao seu critério demográfico, que influencia nas intermediações em escala regional e global. Em escala regional, o município se destaca como uma referência de comércio e serviços especializados para as cidades situadas em seu entorno. Em proporção nacional, a cidade se destaca na contribuição com o desenvolvimento do agronegócio (FERRETTO, 2012).
Nesse sentido, é de extrema importância considerar que a urbanização contemporânea de Passo Fundo, assim como em outras cidades de médio porte, vem se transformando e se caracterizando espacialmente. Essa forma urbana de cidade de médio porte pode ser determinada pelo seu espraiamento físico, pela sua urbanização territorial desorganizada, descontínua e fragmentada. Contudo, também pode ser definida pela sua ocupação urbana com espaços conectados e espaços livres, constituindo uma forma urbana característica de uma cidade de médio porte (FERRETTO, 2012; COCOZZA et al., 2014).

Assim sendo, presume-se que cidades como Passo Fundo, podem apresentar uma quantidade de espaços livres passível de ser considerada como um sistema, agregando várias categorias de espaços e, consequentemente, influenciando na forma e na qualidade urbana e ambiental da cidade. Por isso, este artigo tem como objetivo principal apresentar a relação entre a ocupação urbana e o sistema de espaços livres intraquadra da cidade de Passo Fundo/ RS, a fim de compreender a sua forma urbana contemporânea na interação de diferentes contextos que a compõe.

\section{O Processo de Ocupação Urbana e o Sistema de Espaços Livres}

O Brasil é composto por uma grande variedade morfológica urbana. Tais formas urbanas derivaram da combinação das influências estrangeiras e das características locais, biológicas e, principalmente, antrópicas. Alguns estudos já realizados sobre a morfologia urbana denotam que a forma das cidades brasileiras pode ser estabelecida e detectada pelas lógicas de produção, padrões e classes específicas de tecido urbano, de sistema de espaços livres e de modelos de parcelamento que demonstrem a atual paisagem urbana nacional. No entanto, salienta-se que, em análises de cidades de diferentes portes, ou até mesmo com porte similar, existem especificidades locais que precisam ser conhecidas (Macedo et al., 2018).

Nesse contexto, estudos sobre a ocupação urbana e o sistema de espaços livres na constituição da forma urbana contemporânea 
de Passo Fundo tendem a identificar suas particularidades, buscando investigar como a inter-relação do meio urbano e rural refletem a paisagem local - e vice-versa -, na sua forma e ocupação urbana e na disposição do seu sistema de espaços livres. Para tanto, foi feito uso de conceitos empregues por Magnoli (1982) e Macedo et al. (2018) para o entendimento e aplicabilidade da temática dos espaços livres.

Os espaços livres urbanos segundo Magnoli (1982), são aqueles que compreendem todo o espaço não construído, inclusive as áreas remanescentes da apropriação dos lotes, ruas, parques, praças e áreas de preservação permanente (APP). Já para Macedo et al. (2018, p. 14), o Sistema de Espaços Livres (SEL) não é definido apenas pelos elementos que o compõe, "mas também das relações entre todos os espaços livres de edificações urbanas, independentemente de sua dimensão, de sua qualificação estética e funcional e de sua localização, sejam eles públicos ou privados". Macedo et al. (2018) acreditam que o SEL é aquele em que os espaços livres apresentam relações de conectividade e complementariedade, tanto se eles forem planejados quanto simplesmente implantados em um local.

Dentro deste conceito, Campos et al. (2009) e Campos (2010) definem o estudo dos espaços livres intraquadra como aquele que contém o objetivo de analisar a quantidade de espaços livres no interior das quadras urbanas, independentemente de suas propriedades e usos. Do mesmo modo, para Macedo et al. (2018), os espaços livres intraquadra referem-se a todos os espaços livres inseridos no interior das quadras que compõem a malha urbana, ou seja, todo espaço livre em que se encontra descoberto, seja pavimentado ou vegetado, público ou privado, de origem formal ou informal.

Nesse ponto, a rede Quapá-SEL utiliza como um de seus instrumentos de trabalho a elaboração de mapas temáticos, que visam caracterizar a morfologia urbana das cidades brasileiras, simplificando a compreensão da forma urbana e da sua relação com os espaços livres. Dentre os mapas temáticos desenvolvidos, dois deles se destacam neste artigo: o mapa do processo de ocupação urbana e o mapa do sistema de espaços livres intraquadra (Figura 1).
A relação entre os dois mapas está associada ao reconhecimento do grau de consolidação de áreas de ocupação urbana e ao seu caráter quanto a densidade e os sistema de espaços livres (MACEDO et al., 2018). Ao apurar essa análise, é dada ênfase ao enredo histórico local, à conformação atual de malha urbana e às perspectivas futuras diante do seu constante desenvolvimento.

\section{A Área de Estudo}

A cidade de Passo Fundo está localizada no norte do Estado do Rio Grande do Sul (Figura 2), a 293 km de Porto Alegre, capital do Estado. A região em que Passo Fundo está localizada é chamada de mesorregião Noroeste Rio-grandense, a qual comporta 216 municípios e uma população total em torno de 2 milhões de habitantes, assim tornando-se a segunda maior região com aglomerado populacional do Estado. O município está situado na latitude $28^{\circ} 15^{\prime} 46^{\prime \prime} \mathrm{S}$ e na longitude $52^{\circ} 24^{\prime} 24^{\prime \prime} \mathrm{O}$ (PASSO FUNDO, 2019a; FERRETTO, 2012).

O município se destaca como centro urbano regional, pois é o único da região com população superior a 100 mil habitantes. No último Censo Demográfico, ocorrido no ano de 2010, o Instituto Brasileiro de Geografia e Estatística (IBGE), registrou que a cidade de Passo Fundo contava com um total de 184.826 habitantes (IBGE, 2010a). Com base nas estimativas anuais realizadas pelo IBGE, a cidade de Passo Fundo (2019a) estima que no ano de 2017 a população totaliza 196.739 habitantes. Já em 2018, o IBGE (2019) reconhece que a cidade conta com um total de 201.767 habitantes e, por essa razão, é considerada a $12^{\circ}$ cidade mais populosa do Estado. Ademais, é significativo destacar que concentra $97 \%$ da sua população em área urbana (FERRETTO, 2012), motivo pelo qual se justificam as análises deste estudo se voltarem para a mancha urbana passo-fundense.

Ao levar em consideração o processo histórico de ocupação territorial de Passo Fundo, seu marco inicial aconteceu no século XVII, quando as missões jesuíticas espanholas ocuparam a fração noroeste do estado do Rio Grande do Sul. No século seguinte, o processo de apropriação do território se intensificou graças ao Tropeirismo, 


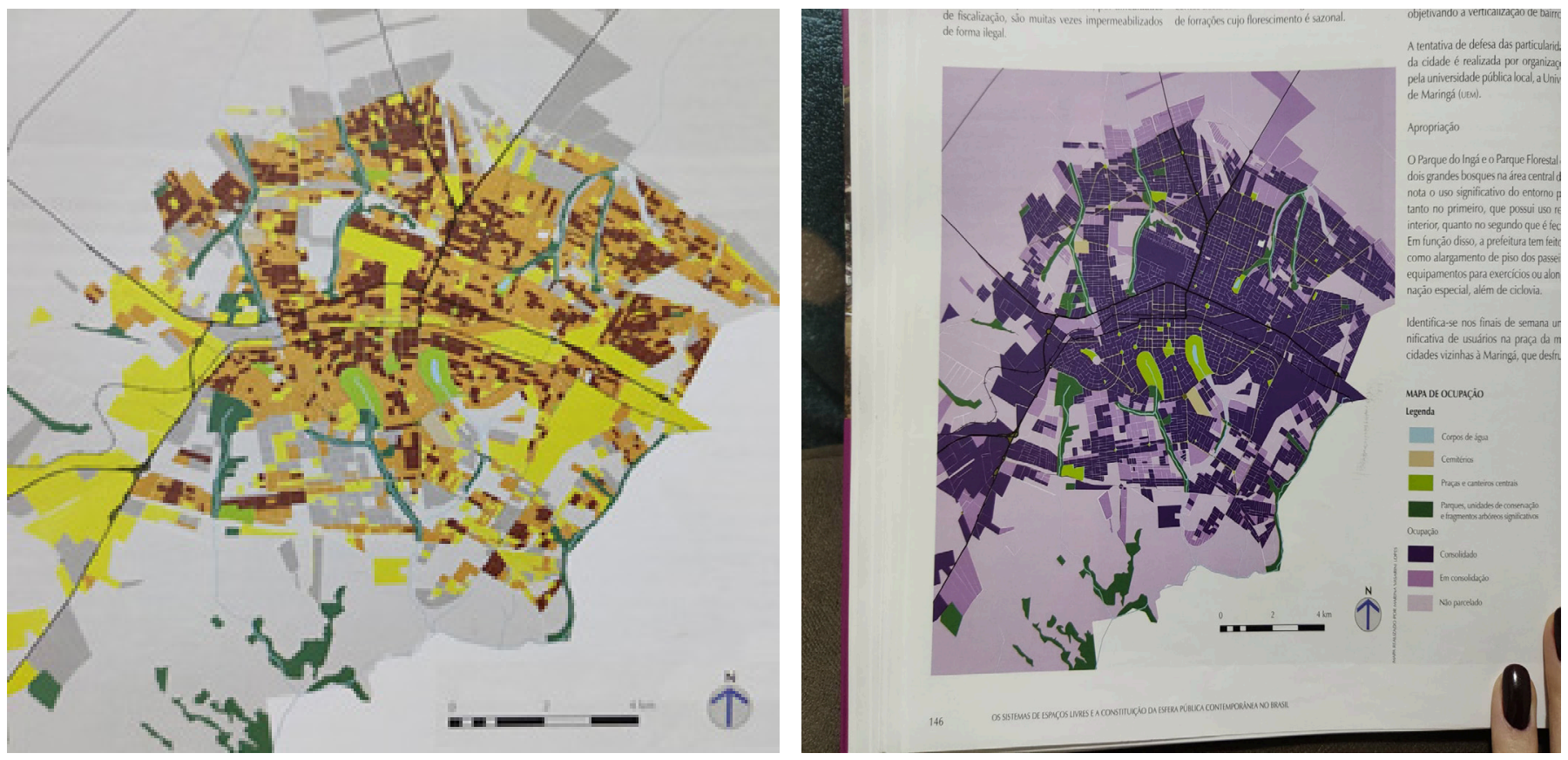

Figura 1. Mapa do processo de ocupação urbana da cidade de Maringá/PR (à esquerda) e o mapa do sistema de espaços livres intraquadra da cidade de Maringá/PR (à direita).

Fonte: MACEDO et al., (2018, p. 146 e 148).

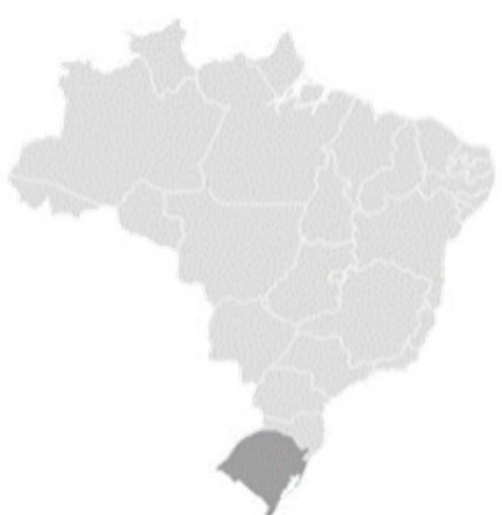

Brasil

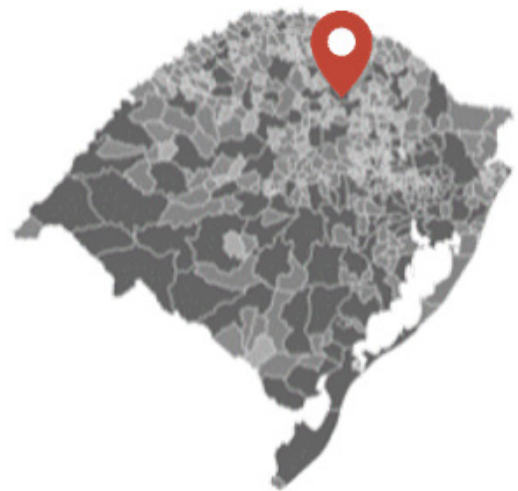

Rio Grande do Sul

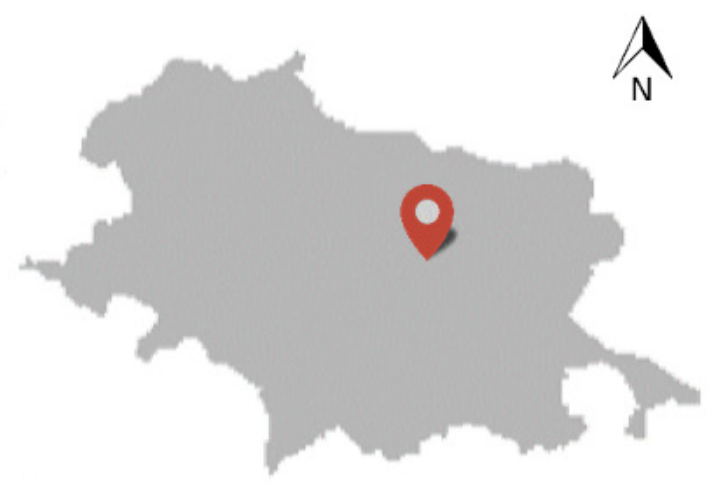

Passo Fundo

Figura 2. Localização geográfica de Passo Fundo.

Fonte: Autores (2019), segundo imagens online. 
que incluiu o local em seu trajeto, marcado pelo deslocamento e comercialização de animais com potencial para o transporte de mercadorias e pessoas (FERRETTO, 2012; IBGE, 2010b).

No decorrer dos séculos XVIII e XIX, os primeiros colonizadores povoaram a região conhecida como Planalto Médio Gaúcho, fazendo dessa parada obrigatória para pernoite dos tropeiros, oriundos da fronteira sul e com destino à Província de São Paulo, assim, tornando-se parte integrante do chamado "Caminho dos Tropeiros" (FERRETTO, 2012; IBGE, 2010b). Durante o trajeto, os tropeiros estruturaram muitos povoados, os quais futuramente se tornaram municípios, a exemplo da cidade de Passo Fundo (GOSCH 2002; FERRETTO, 2012; IBGE, 2010b).

No século XIX, a região recebeu fazendeiros, vindos da região central do Brasil. "Formavam-se, assim, a grande propriedade fundiária e a sociedade senhorial escravocrata, que viriam a caracterizar a ocupação de Passo Fundo" (RODIGHERI, GEHM, BITENCOURT, 2004, p. 78). No decorrer desse período, a cidade iniciava lentamente sua estruturação urbana. O ano de 1857 é um marco na história para Passo Fundo, pois passou a categoria de Município (FERRETTO, 2012; IBGE, 2010b).

Ainda nesse século, estrutura-se a estrada de ferro e a organização de empresas colonizadoras que buscavam grandes terras para serem compradas, subdivididas em lotes e revendidas à população. A implantação da ferrovia propiciou a cidade se desenvolver na vizinhança da estação férrea e assegurou um bom desenvolvimento da industrialização, da segurança nacional e do crescimento de uma modernização local (FERRETTO, 2012).

Do final do século XIX até metade do XX, o crescimento da cidade está concentrado na área central da cidade, próximo à estação férrea. No período entre as décadas de 1900 a 1940, no que tange à economia local, o desenvolvimento das estradas levou aos comerciantes rurais o acesso para as negociações de produtos na cidade (TEDESCO; SANDER, 2005). Com o decorrer do tempo, Tedesco e Sander (2005) evidenciam que além da agricultura de subsistência surgiu a agricultura comercial, acentuando as relações comerciais na evolução do desenvolvimento econômico de Passo Fundo.
O início da década de 1950, caracteriza-se um novo período graças a intensa lógica de produção da cidade quando, nesse período, os loteamentos periféricos marcaram o crescimento urbano horizontal e uma inicial verticalização na área central da cidade começava a nascer (FERRETTO, 2012). Nessa mesma década, é desenvolvido o primeiro Plano Diretor da cidade de Passo Fundo, figurando o município como polo regional (GOS$\mathrm{CH}, 2002)$

Durante as décadas de 1970 e 1980, novos limites urbanos foram criados. O centro da cidade ganha destaque com sua verticalização crescendo a cada ano. Nesse mesmo período, verificam-se as primeiras ocupações irregulares e de alto risco em áreas rurais com potencial para urbanização e ao longo do rio Passo Fundo. A via férrea instaurada em 1897 é retirada e reformulada em um posicionamento estratégico na busca por demarcar a malha urbana de Passo Fundo. Com o mesmo objetivo, formam-se as vias perimetrais, reforçando o controle no crescimento espraiado da cidade e definindo o seu perímetro urbano. (FERRETTO, 2012; PASSO FUNDO, 2019b).

No período que se aproxima ao ano 2000, a cidade de Passo Fundo é marcada pelo seu alto desenvolvimento na agricultura - deixando de lado a policultura e focando nas monoculturas de trigo e soja - que moderniza e evolui para um complexo agroindustrial regional (FERRETTO, 2012). Desde então, a cidade cresceu horizontalmente e verticalmente, e somente com a criação do segundo Plano Diretor de Desenvolvimento Integrado (PPDI) houve a preocupação de conter a expansão horizontal da cidade e conduzir o crescimento de forma mais ordenada, compelindo a ocupação de áreas vazias (PASSO FUNDO, 2018). Com esse novo instrumento de política urbana, houve a composição de um zoneamento urbano, o qual passou a designar índices de aproveitamento na área central da cidade, instaurando-se nesse momento os fenômenos do adensamento urbano central e da especulação imobiliária (GOSCH, 2002; FERRETTO, 2012; PASSO FUNDO, 2019b). Toda essa evolução da ocupação urbana de Passo Fundo encontra-se concisamente ilustrada na Figura 3. 


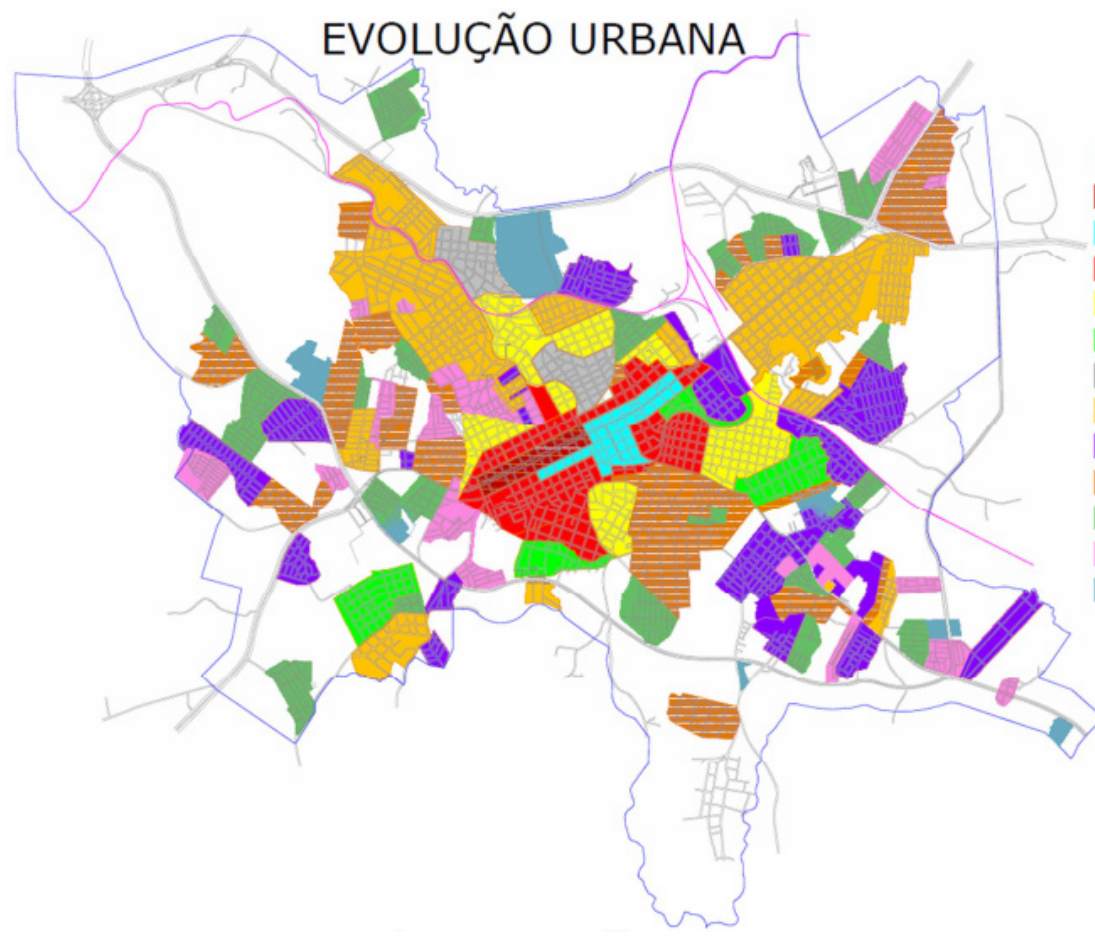

EVOLUÇĂO URBANA

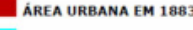

ATÉ FINS Do século

aTé 1922

ATÉ 1929

DE 1930 A 1939

DE 1940 A 1949

DE 1950 A 1959

DE 1960 A 1969

DE 1970 A 1979

DE 1980 A 1989

DE 1990 A 1999

DE 2000 A 2018

Figura 3. Evolução urbana da cidade de Passo Fundo/RS. Fonte: PASSO FUNDO (2018, p. 200).

Atualmente, no que se refere à economia, Passo Fundo desempenha uma função de destaque no Estado, porque atua como um centro regional de importante papel, pois apresenta uma porcentagem de $60,97 \%$ das suas riquezas concentradas no setor de serviços - área da saúde, educação superior, investimentos imobiliários e pesquisas na área agrícola -, 22,94\% na indústria e $16,25 \%$ na agropecuária e agronegócios, além de sediar importantes eventos culturais, a exemplo do Festival Internacional do Folclore, Jornada Nacional da Literatura e outros (FERRETTO, 2012; MASCARÓ; BONATTO, 2014). No setor terciário, a existência de dois shoppings - o Shopping Bella Cittá, presente na cidade há mais de 20 anos, situado no centro da cidade, e o Passo Fundo Shopping, recentemente inaugurado em 2018, no bairro São Cristóvão - , a presença de diversos serviços de saúde e as opções de ensinos superiores, faz com que Passo Fundo amplie seus laços com municípios de toda a região (MASCARÓ; BONATTO,
2014). Nessa conjuntura, fica evidente a sobreposição de funções que a cidade de Passo Fundo apresenta.

Dado o breve histórico de ocupação territorial e seu relevante papel econômico de destaque regional, o núcleo regional que se desenvolveu desde então ocorreu por inúmeras razões, até a cidade se tornar de porte médio, como é hoje em dia. Em vista disso, diversos tipos de espaços livres com funções próprias orientaram os primeiros traçados desse território que, ao longo dos anos, somaram-se a outros modelos de parcelamento, conformando as tramas urbanas atuais.

\section{Procedimentos Metodológicos}

O estudo se define por uma abordagem qualitativa, pois buscou compreender a forma urbana da cidade por meio de suas 
características locais. O método utilizado no desenvolvimento do estudo detém como referência principal os estudos sobre os sistemas de espaços livres urbanos desenvolvidos pelo grupo Quapá-SEL.

A seleção de dados da mancha urbana de Passo Fundo - bases cartográficas e levantamento aerofotogramétrico - foi adquirida via acervo técnico da Prefeitura Municipal (PASSO FUNDO, 2018). Foram adquiridos dados demográficos e espaciais e dados vetoriais (em formato shapefile) por meio do Censo de 2010, realizado pelo IBGE. De forma a complementar, foi realizada a verificação por imagens via satélite e visitas em campo.

O tratamento dos dados foi desenvolvido por meio da técnica de geoprocessamento, mediante o uso de um Sistema de Informações Geográficas (SIG). Nesse caso, o software utilizado foi o QGIS, o qual dispõe de um código aberto e é uma ferramenta que permite criar, visualizar e analisar mapas e dados. No sistema operacional QGIS, para o estudo da forma urbana da cidade de Passo Fundo, foi levado em consideração a malha urbana atual da cidade por meio do Plugin QuickMapServices, compatível com a interface gráfica do programa, e o acesso foi feito pela ferramenta Google Satellite.

Para que houvesse êxito nas análises, foi empregado o Sistema de Referência Geocêntrico para as Américas, o SIRGAS 2000, e adotado o UTM (Universal Transversa de Mercator) zona 22S (Sul), como coordenada ortogonal (EPUSP, 2015), pois é nessa em que o município de Passo Fundo se localiza. A partir disso, a avaliação por meio de arquivos georreferenciados pôde ser realizada a partir do método sistemático de interpretação de imagens (Moreira, 2005), isto é, por meio do recurso da fotointerpretação via satélite, foi possível identificar as atuais condições de ocupação urbana de Passo Fundo.

Logo, foram efetuados análises e mapeamentos da mancha urbana da cidade. Em um primeiro momento, para a compreensão do processo de ocupação urbana, foi considerando as classificações descritas por Macedo et al. (2018), como: a. Consolidado

b. Em consolidação

c. Não parcelado

Em seguida, para o entendimento do sistema de espaços livres urbanos de Passo Fundo, também foi levada em consideração a classificação que Macedo et al. (2018) definiram como porcentagem quanto à existência de espaços livres em relação ao total de área ocupada pela quadra, sendo elas:

a. Até $30 \%$ da área de quadra livre de edificações

b. De $30 \%$ a $50 \%$ da área de quadra livre de edificações

c. Mais de $50 \%$ da área de quadra livre de edificações

Por fim, no processo de classificação e criação dos mapas, utilizou-se recursos previamente estabelecidos. Um deles foi o uso de cores, o qual foi levado em consideração o padrão de cores utilizado pelo grupo de pesquisa QUAPÁ-SEL, que já desenvolve estudos sobre a forma urbana das cidades brasileiras desde 2005 e, por isso, possui um vasto acervo de estudos teórico-metodológico nessa linha de pesquisa. Segundo o grupo, as cores utilizadas em seus estudos estão diretamente correlacionadas com as informações transmitidas, ou seja, o emprego de cores escuras identifica as áreas de ocupação mais densas e o emprego de cores mais claras caracterizam as áreas com menor ou nenhuma construção.

\section{Resultados e Discussão}

Em um primeiro momento, a forma urbana de Passo Fundo se manifesta como uma mancha urbana tentacular, isto é, àquela constituída por um núcleo central compacto que lançam braços de urbanização por toda extensão de seus eixos viários. Porém, pressupõe-se que a forma urbana de Passo Fundo pode se classificar de forma compacta e contínua, dado que sua expansão temporal (Figura 3) tem se manifestado de forma contínua em todos os sentidos, contornando elementos naturais - bosques, rodovias, ferrovias e lagoas -, tidos como obstáculos, de modo 


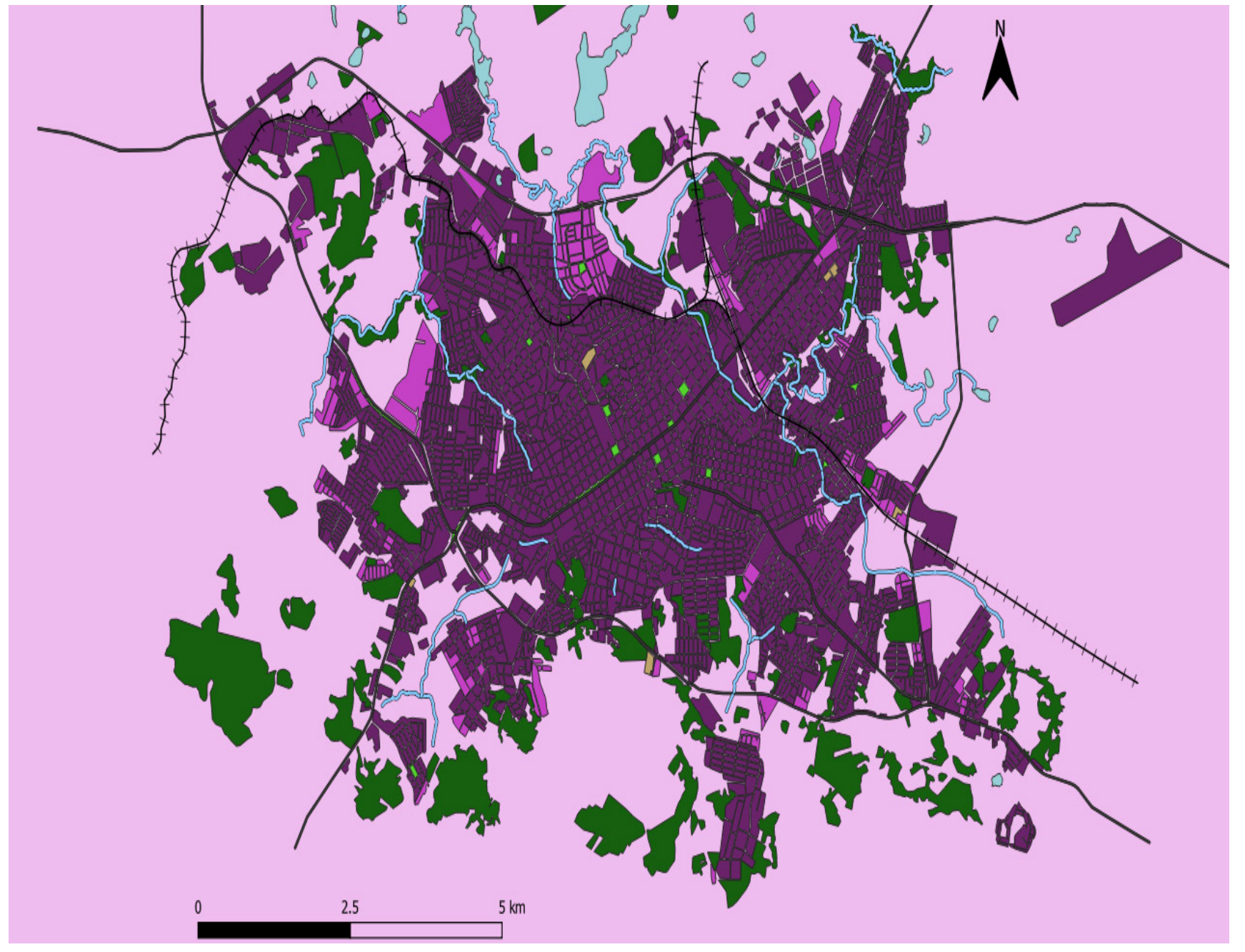

Legenda

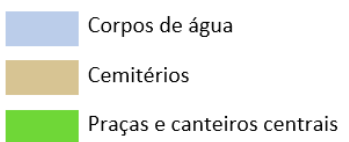

Praças e canteiros centrais

Parques, unidades de conservação e fragmentos arbóreos significativos

Ocupação

Consolidado

Em consolidação

Não parcelado

Figura 4. Mapa de ocupação urbana de Passo Fundo.

Fonte: Autores (2019) elaborado no Software QGIS com auxílio da ferramenta Google Sattelite.

natural. Portanto, presume-se que Passo Fundo contém um sistema de espaços livres inserido em uma mancha urbana compacta (Figura 4).

A partir da identificação desse mapa de ocupação urbana de Passo Fundo (Figura 4) e ao considerar o mapa da evolução urbana (Figura 3), as análises evidenciam um contínuo espraiamento de edificações em todos os sentidos nos últimos anos. Porém, esse crescimento de ocupação urbana não se sobressalta ao que já vinha ocorrendo em tempos anteriores, não descaracterizando a forma urbana da cidade.

Assim, inicialmente, fez-se uso do método descrito por Moreira (2005), a fotointerpretação quadra a quadra da cidade de Passo 
Fundo, em busca da identificação e da quantidade de espaços livres disponíveis em cada uma. As Figuras 5, 6 e 7, representam a classificação apontada por Macedo et al. (2018), retratando os espaços livres de cada quadra pela cor branca e as áreas ocupadas por edificações pela cor preta.

A Figura 5 retrata um exemplo de quadra em Passo Fundo com a classificação de até $30 \%$ de espaços livres intraquadra. Nesse caso, é evidente que a quadra em destaque apresenta excessiva apropriação às taxas de ocupação do solo urbano, categoria muito presente no centro da cidade e, em alguns casos específicos, em bairros periféricos da malha urbana. O que os diferencia são seus distintos graus de verticalidade e, por vezes, seus tipos de pavimentações, mas o que o centro e esses característicos bairros apresentam em comum são suas excessivas ocupações pelo mínimo espaço de terra urbana.
A Figura 6 apresenta um exemplo de quadra com a classificação com $30 \%$ a $50 \%$ de espaços livres intraquadra. Essa categoria chama muito a atenção na malha urbana de cidades de médio porte, pois são tipos de quadras que se pulverizam por toda extensão territorial urbana. Aliás, como forte característica, essas quadras contêm um equilíbrio entre o espaço não construído e o construído, os distribuindo quase que igualmente sobre o terreno. Assim, por conterem boas proporções intraquadra e generosa distribuição espacial na malha urbana, tal categoria tem um importante papel na forma urbana das cidades de médio porte.

A Figura 7 demonstra um exemplo de quadra com a classificação de mais de $50 \%$ de espaços livres intraquadra. Nessa categoria o espaço livre ganha maiores proporções do que a área construída, com predominância de grandes espaços livres de ajardinamento
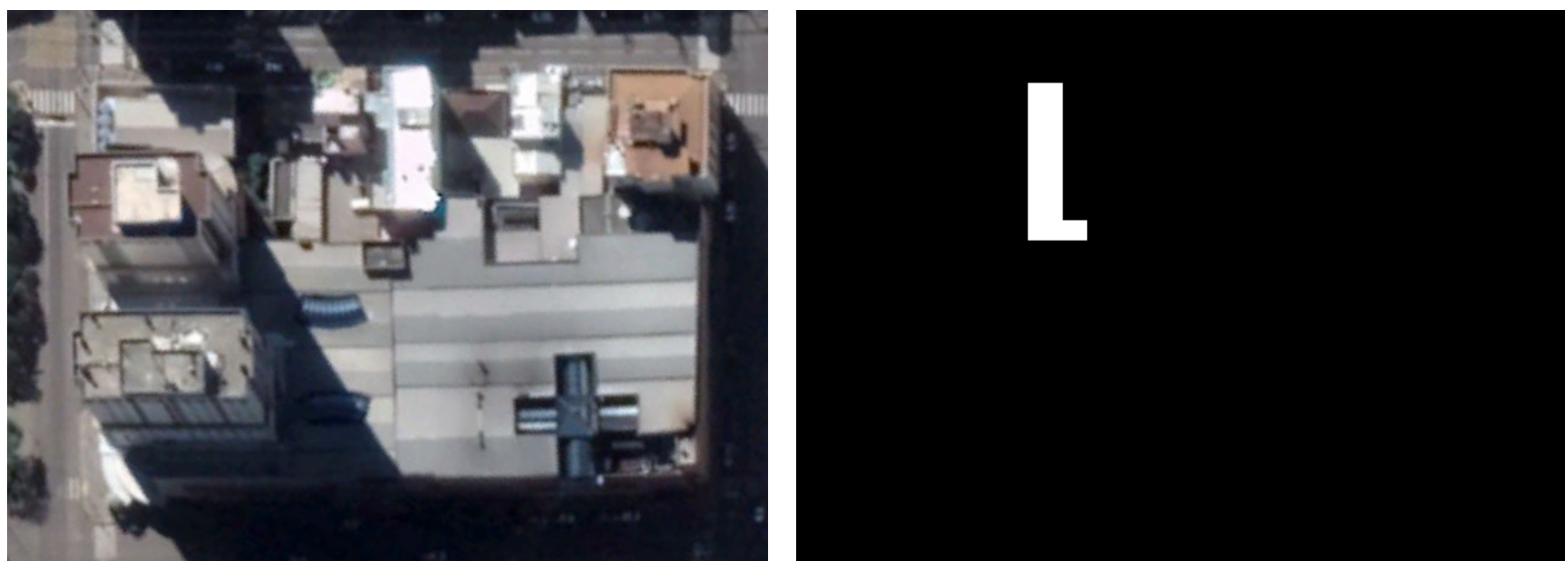

Figura 5. Modelo de quadra densamente construída, quase exclusivamente localizada no setor central da cidade de Passo Fundo (à esquerda) e sua classificação de até $30 \%$ de espaços livres intraquadra (à direita).

Fonte: Autores (2019) segundo Google Sattelite. 

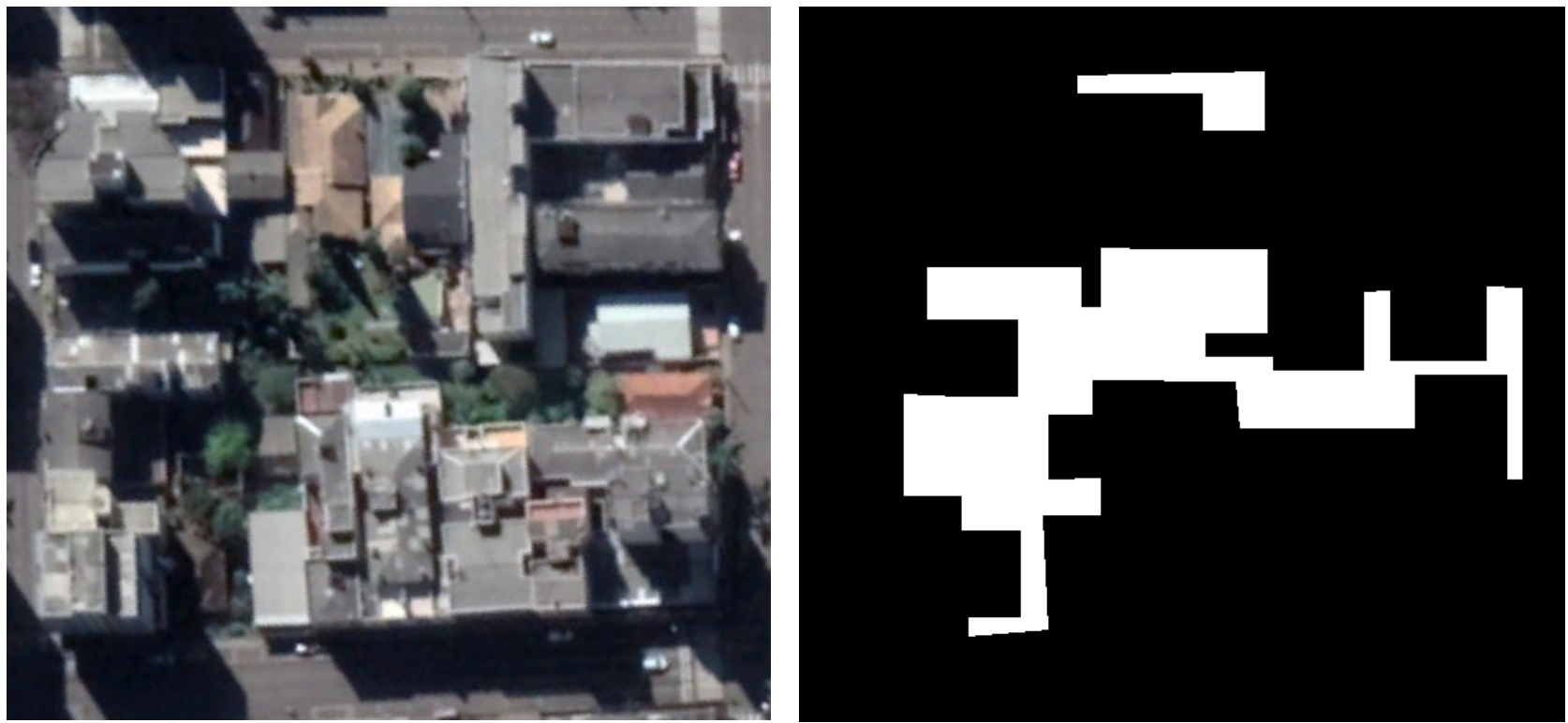

Figura 6. Modelo de quadra localizada tanto no setor central da cidade de Passo Fundo como em vários outros setores (à esquerda) e sua classificação com $30 \%$ a $50 \%$ de espaços livres intraquadra (à direita). Fonte: Autores (2019) segundo Google Sattelite.
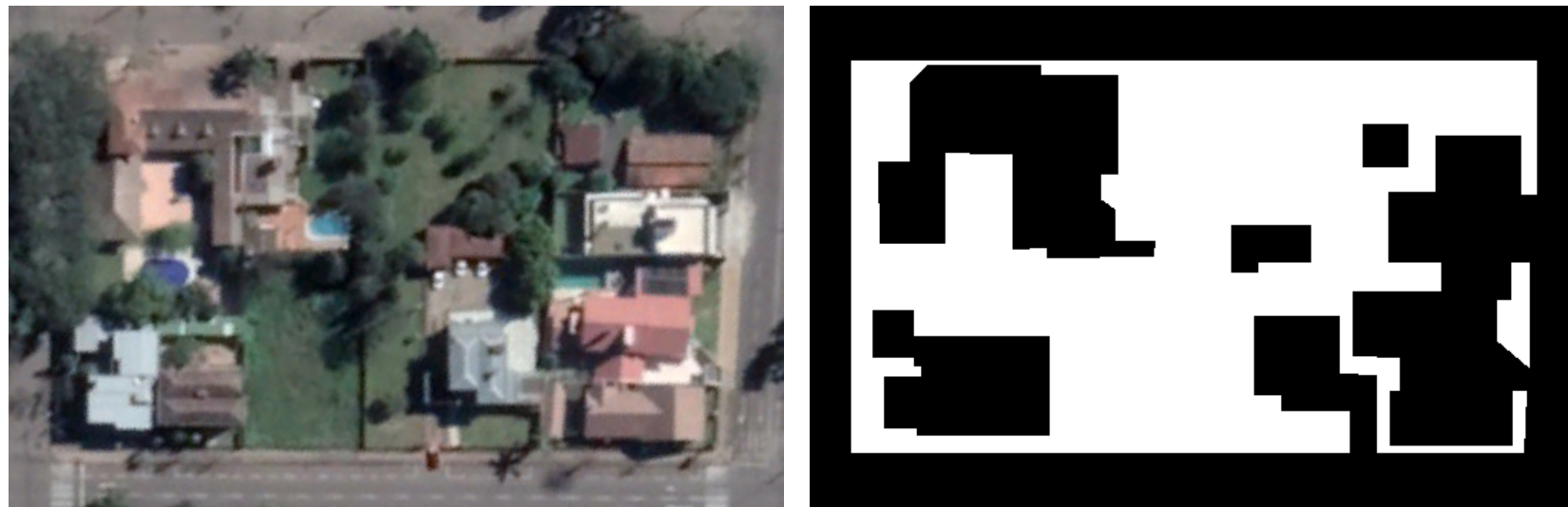

Figura 7. Modelo de quadra localizada em setores mais afastados da região central da cidade de Passo Fundo (à esquerda) e sua classificação de mais de $50 \%$ de espaços livres intraquadra (à direita).

Fonte: Autores (2019) segundo Google Sattelite. 
e recuos, característica de quadras mais afastadas do centro da cidade e/ou pertencentes a bairros estritamente residenciais.

Desse modo, após considerar a classificação de espaços livres intraquadra propostas por Macedo et al. (2018) e constatá-las na malha urbana da cidade de Passo Fundo, desenvolveu-se o mapa do sistema de espaços livres intraquadra (Figura 8). Para desenvolver o mapeamento, foi levado em consideração as três categorias expostas anteriormente - até $30 \%$ de espaços livres intraquadra, de $30 \%$ a $50 \%$ de espaços livres intraquadra e mais de $50 \%$ de espaços livres intraquadra -, áreas em consolidação, áreas não consolidadas e os tipos de cobertura do solo - corpos de água, cemitérios, praças e canteiros centrais, parques, unidades de conservação e fragmentos arbóreos significativos.

Ao observar os dois mapeamentos (Figura 4 e Figura 8), observase $o$ adensamento construído nas áreas urbanas consolidadas. Em vista disso, constata-se uma predominância de tecidos urbanos com até $30 \%$ de espaços livres na área central da cidade (Figura 9) e, em alguns pontos periféricos (Figuras 10, 11 e 12).

A maior concentração de mancha urbana com até 30\% de espaços livres intraquadra encontra-se localizada no centro da cidade (Figura 9). Essa predominância é justificada pelo processo histórico de ocupação territorial de Passo Fundo, pois essa região acondiciona as primeiras edificações desde a fundação da cidade, e por conter, desde então, sucessivas e variadas formas de ocupação urbana.

Diferentemente do cenário central, mas apresentando a mesma característica de porcentagem, constata-se pontos de adensamento com até $30 \%$ de espaços livres intraquadra espalhados pela malha urbana da cidade. As Figuras 10 e 11 apresentam um exemplo dessa classificação, sendo que são casos de assentamentos de classe baixa e situados em uma área suburbana, com uma concentração edilícia excedente ao permitido e se destacando das demais ao seu entorno.

Ainda nesse mesmo contexto, a Figura 12 representa uma característica comum em cidades que abrigam ferrovias e Passo
Fundo é uma delas. Dado o processo histórico anteriormente apresentado, ao considerar a implantação da ferrovia, sua posterior mudança de percurso e até a sua atual presença, a dinâmica de apropriação em seu entorno é um importante aspecto a ser considerado diante da forma urbana da cidade. Assim, o estudo conseguiu comprovar que, em determinadas regiões, a ocupação beira-trilhos e arredores apesentam alto índice construtivo, conforme demonstra a Figura 12.

Diante dos quatro exemplos de até $30 \%$ de espaços livres intraquadra delineados - centro, bairros e beira-trilhos -, recorda-se que o alto grau de impermeabilização e sistema construtivo pode acarretar dificuldades de escoamento da água pluvial e mínimas porções de espaços vegetados e de lazer. Mesmo que atualmente as intempéries causarem problemas eventuais na malha urbana de Passo Fundo (O NACIONAL), as características decorrentes deste estudo mostram que causas maiores de enchentes poderão se tornar um problema futuro.

Acredita-se que a porcentagem de $30 \%$ a $50 \%$ de área de quadra livre de edificações apresenta um melhor equilíbrio entre a área construída e não construída e a sua generosa distribuição pela malha urbana de Passo Fundo demonstra uma otimista manifestação. Outra característica verificada é a mistura de tecidos com $30 \%$ a $50 \%$ e de mais de $50 \%$ de espaços livres intraquadra em praticamente toda a extensão da malha urbana. Acredita-se que esse aspecto seja positivo, dado que o cruzamento dessas características de espaços livres contribui para a dinâmica climática diária de insolação e ventilação, grandes espaços permeáveis e presença de áreas verdes.

Além do mais, a característica que corrobora a importância de uma boa estruturação dos sistemas urbanos de espaços livres intraquadra e viário é que, em sua grande maioria, os espaços livres intraquadra de Passo Fundo pertencem à propriedade privada, com alguns casos pontuais públicos (praças e canteiros) e excepcionalmente com espaços públicos de propriedade privada (POPS). Entende-se, assim, que há mais espaços livres intraquadra com restrição de acesso, seja por edificações sem ajardinamento 


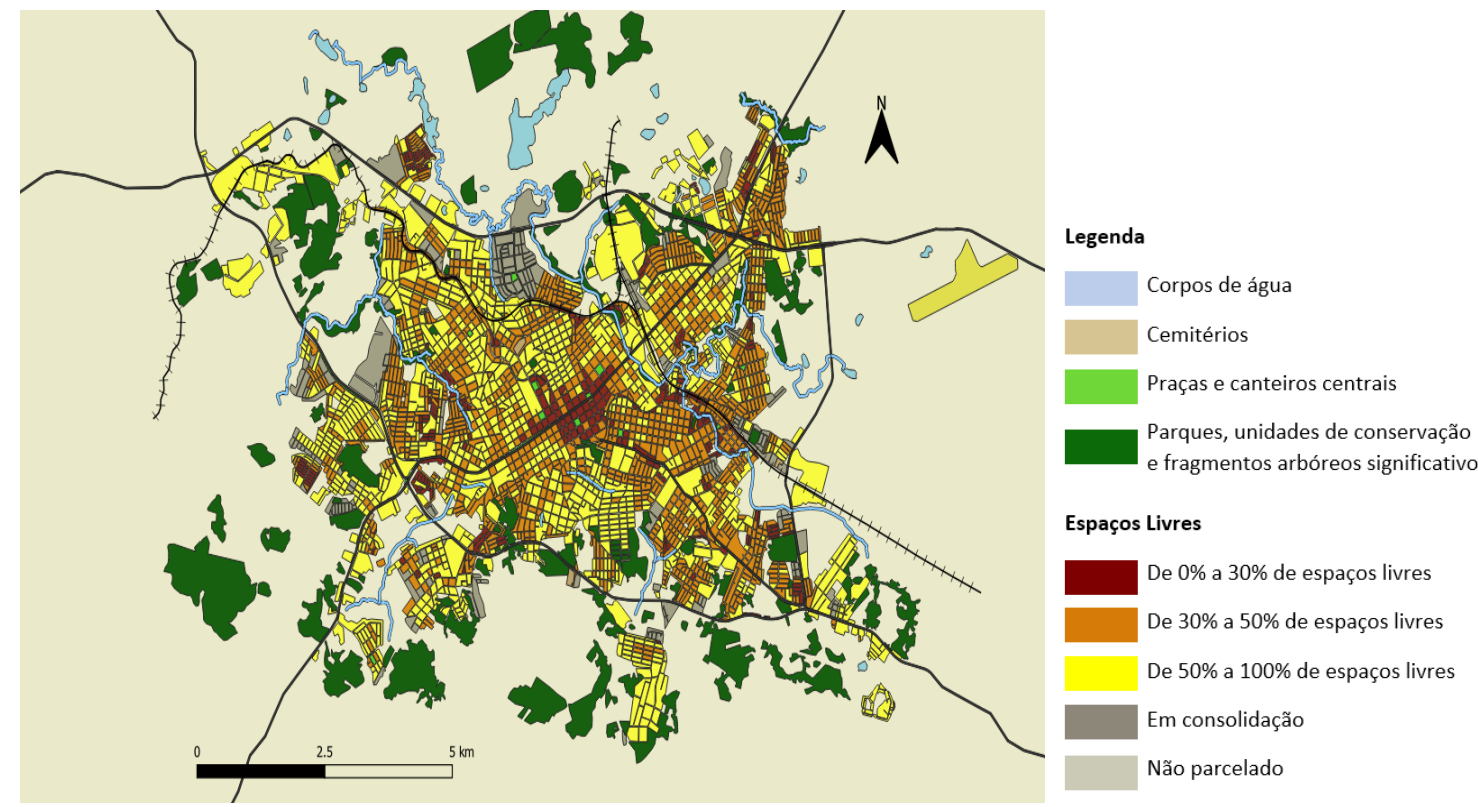

Figura 8. Mapa do sistema de espaços livres intraquadra de Passo Fundo.

Fonte: Autores (2019) elaborado no Software QGIS com auxílio da ferramenta Google Sattelite.
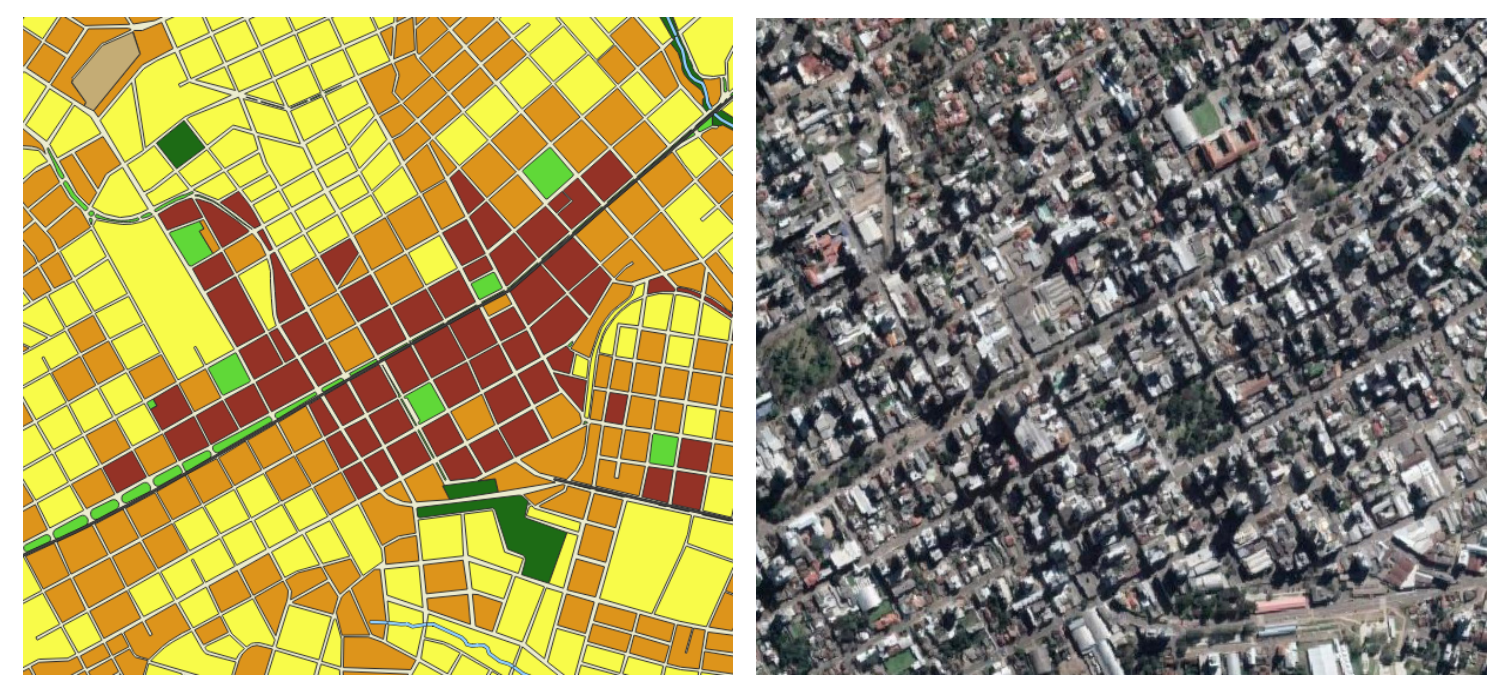

Figura 9. Reconhecimento de tecidos urbanos com até $30 \%$ de espaços livres na área central da cidade de Passo Fundo.

Fonte: Autores (2019) elaborado no Software QGIS com auxílio da ferramenta Google Sattelite. 
no recuo frontal ou pela existência de muros, demonstrando o pouco contato direto com o sistema viário urbano do município.

Esse misto de tecidos traz o questionamento sobre a observância (ou não) das normativas do plano diretor municipal por parte da população na hora de edificar e pavimentar os espaços livres intraquadra e do planejamento e gestão dos sistemas urbanos por parte do poder público no momento da fiscalização. É importante que haja um alinhamento do planejamento com a gestão do sistema de espaços livres intraquadra e o sistema viário municipal, pois eles influenciam em diversos projetos e planos de ação municipal que tem a intenção de propor a integração e otimização entre os diferentes sistemas que compõem o SEL. Ou seja, um frágil planejamento e gestão urbana dos sistemas de espaços livres intraquadra e viário, comprometem a busca pela qualidade dos espaços livres urbanos nas cidades de médio porte brasileiras.

Nenhum dos autores mencionados neste estudo atestam como ideal uma determinada porcentagem de espaços livres intraquadra que uma cidade de médio porte deve conter para melhor qualificar o seu SEL. Tampouco, uma quantidade ideal ou, até mesmo, uma distribuição exemplar de um sistema de espaços livres intraquadra. Por isso, o estudo não se deteve em classificar qualitativamente, mas se baseou em características atuais e fatos históricos para descrever e caracterizar a mancha urbana de Passo Fundo.

Em síntese, os mapas de ocupação urbana e de espaços livres de edificação intraquadra foram capazes de expor a alta densidade construída consolidada na cidade e a baixa incidência de espaços livres intraquadra na região central e pontos periféricos, que se- gundo Campos (2010), são características recorrentes nas grandes e médias cidades brasileiras.

\section{Considerações Finais}

Entendeu-se como é importante abordar o processo histórico de Passo Fundo e a sua dinâmica atual como uma cidade de médio porte, de modo a auferir conhecimento sobre a cidade e com o objetivo de realizar os mapas e análises sobre a ocupação urbana e o sistema de espaços livres. Além disso, os dois mapas temáticos da cidade de Passo Fundo contribuem na caracterização da morfologia urbana das cidades de médio porte, facilitando a percepção e a compreensão da forma urbana, bem como, a sua relação com os seus espaços livres.

Em um apanhado geral, as características encontradas até o presente momento, ou seja, de ocupação urbana e de espaços livres intraquadra, podem representar o alto grau de consolidação urbana no centro da cidade e em regiões de caráter completamente diferentes e também possuir a presença de tecidos urbanos densos. Por isso, acredita-se que o contínuo desenvolvimento desses estudos locais pode conferir dados de altos índices de impermeabilização, problemas de insolação e ventilação da cidade.

Por fim, acredita-se que, assim como o estudo desenvolvido por Macedo et al. (2018), este artigo contribuirá tanto para a melhor compreensão sobre a temática e a forma urbana das cidades brasileiras, como também, para o desenvolvimento de políticas públicas que busquem a melhoria na qualidade de vida nos espaços urbanos das cidades de médio porte brasileiras. 

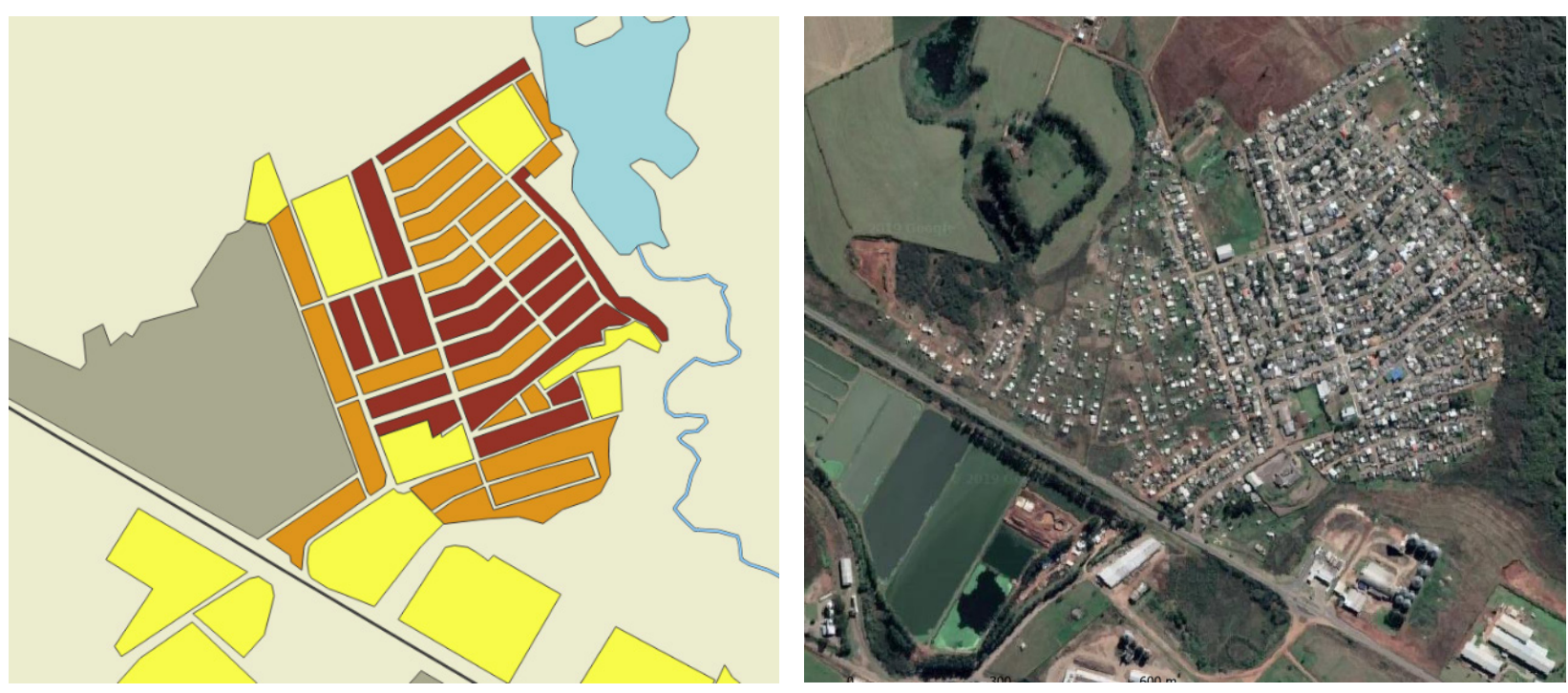

Figura 10. Constatação de tecidos urbanos com até $30 \%$ de espaços livres em áreas periféricas de Passo Fundo. Este caso refere-se ao Bairro José Alexandre Zachia.

Fonte: Autores (2019) elaborado no Software QGIS com auxílio da ferramenta

Google Sattelite.
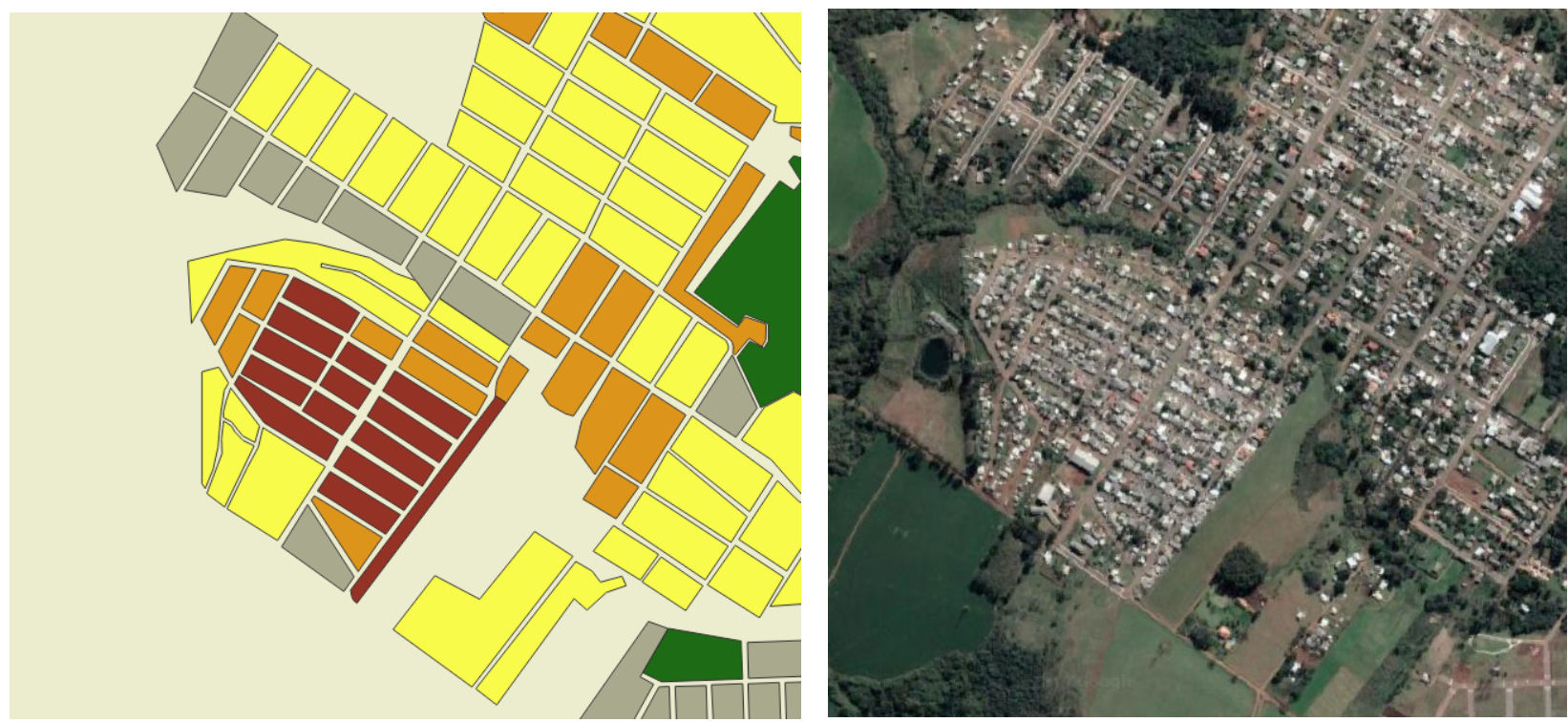

Figura 11. Constatação de tecidos urbanos com até $30 \%$ de espaços livres em áreas periféricas de Passo Fundo. Este caso refere-se ao Bairro Loteamento Jaboticabal.

Fonte: Autores (2019) elaborado no Software OGIS com auxílio da ferramenta Google Sattelite. 

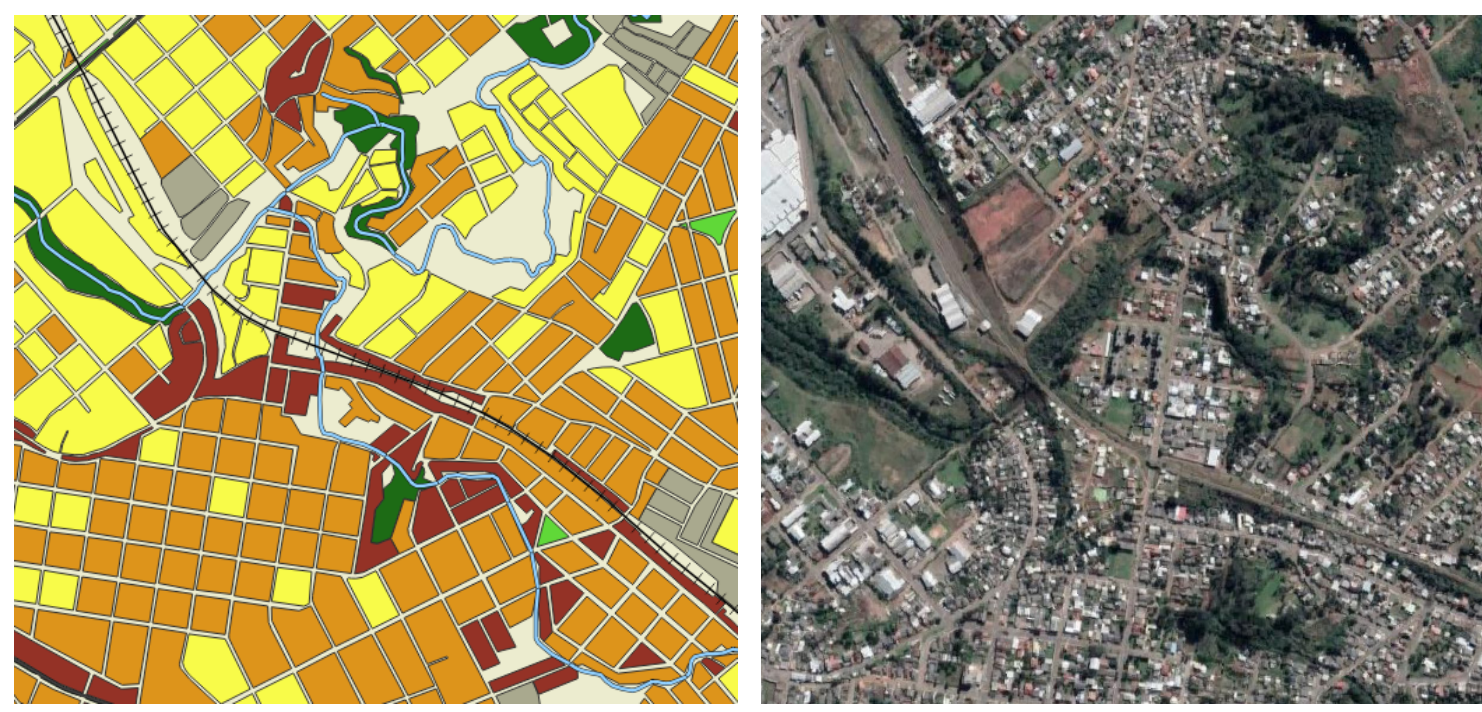

Figura 12. Constatação de tecidos urbanos com até $30 \%$ de espaços livres em áreas periféricas de Passo Fundo. Este caso abrange os Bairros Loteamento Estação Nova e Santa Marta.

Fonte: Autores (2019) elaborado no Software QGIS com auxílio da ferramenta Google Sattelite.

\section{ReferênCIAS Bibliográficas}

CAMPOS, A.C. M. A. Análise do Sistema de Espaços Livres da cidade brasileira: uma metodologia em elaboração. In: ENCONTRO NACIONAL DA ASSOCIAÇÃO NACIONAL DE PESQUISA E PÓS-GRADUAÇÃO EM ARQUITETURA E URBANISMO, 1, 2010, Rio de Janeiro. Anais... Rio de Janeiro: ANPARQ, UFRJ, UFF, 2010, p. 1-22.

CAMPOS, A.C. M. A; COSSIA, D.; MACEDO, S. S.; PRETO, M. H.; ROBBA, F. Análise do Sistema de Espaços Livres da cidade brasileira - uma metodologia em construção: estudo de caso para o município de São Paulo. Paisagem e Ambiente: ensaios. São Paulo: FAUUSP, v. 26, 2009, p. 197- 210.

COCOZZA, G. P.; GUERRA, M.E. A.; FERREIRA, W. R.; COLESANTE, M. N.; FOUQUET, F.; RIOS, A. L. M. Forma urbana e espaços livres nas cidades médias do Triângulo Mineiro e Alto do Paranaíba. Paisagem e Ambiente: ensaios. São Paulo: FAUUSP, v. 33, 2014, p. 127- 136.

EPUSP. Escola Politécnica da Universidade de São Paulo. Departamento de Engenharia e Transportes - PTR e Laboratório de Topografia e Geodésia - LTG. Sistema UTM. 2015. Disponível em: https://edisciplinas.usp.br/pluginfile.php/1738554/mod_resource/ content/1/PTR0101\%20\%20Proje\%C3\%A7\%C3\%A3o\%20UTM\%20v2015.pdf. Acesso em: 20 maio 2019.

GOSCH, L. R. M. Passo Fundo, de Saturnino de Brito ao Mercosul: projeto e imagens urbanas. Dissertação (Mestrado em Arquitetura e Urbanismo) - Universidade Federal do Rio de Janeiro, Rio de Janeiro, 2002.
IBGE. Instituto Brasileiro de Geografia e Estatística. Censo Demográfico - 2010. Rio de Janeiro: IBGE, 2010a. Disponível em: www.ibge.gov.br/home/estatistica/populacao/ censo2010/. Consultado em: 20 maio 2019.

IBGE. Instituto Brasileiro de Geografia e Estatística. Noticias. Censo 2010: população do Brasil é de 190.732.694 pessoas. 2010b. Disponível em:

$\mathrm{https}: / /$ censo2010.ibge.gov.br/noticias-censo.html?busca=1\&id=3\&idnoticia=1766\&t=censo-2010-populacao-brasil-190-732-694-pessoas\&view=noticia.

Consultado em: 20 maio 2019

IBGE. Instituto Brasileiro de Geografia e Estatística. Passo Fundo. 2019. Disponíve em: https://cidades.ibge.gov.br/brasil/rs/passo-fundo/panorama. Consultado em: 30 maio 2019.

FERRETTO, D. Passo Fundo: estruturação urbana de uma cidade média gaúcha. 2012 176 f. Dissertação de Mestrado, Universidade de São Paulo, São Paulo. 2012.

MACEDO, S. S.; QUEIROGA, E. F.; CAMPOS, A. C. A.; GALENDER, F.; CUSTÓDIO, V. Os Sistemas de Espaços Livres e a Constituição da Esfera Pública Contemporânea no Brasil. São Paulo, EDUSP. 416p. 2018.

MAGNOLI, M. M. Espaços livres e urbanização: uma introdução a aspectos da paisagem metropolitana. 1982. 116 p. Tese de doutorado, Universidade de São Paulo, São Paulo, 1982.

MASCARÓ, Juan J.; BONATTO, Daniella A. M. O sistema de espaços livres de Passo Fundo-RS: escassez e descontinuidade. IX Colóquio QUAPÁ-SEL. 2014. 
MATÉ, C. A cidade pequena através de seu sistema de espaços livres: o caso de Pinhalzinho/SC. 2016. 210 f. Dissertação de Mestrado, Universidade Federal de Santa Catarina, Florianópolis. 2016

MATÉ, C.; SANTIAGO, A. G. Espaços livres privados nas pequenas cidades. Paisagem e Ambiente. São Paulo, v.1, n. 40, p. 59-85, 2017.

MOREIRA, M. A. Fundamentos do sensoriamento remoto e metodologias de aplicação. 3 ed. Viçosa, Minhas Gerais: UFV, 320p. 2005.

O NACIONAL. Cinco bairros de Passo Fundo foram mais atingidos pela chuva. Disponível em: http://www.onacional.com.br/geral/cidade/73195/cinco+bairros+de+passo+fundo+foram++mais+atingidos+pela+chuva. Consultado em: $11 \mathrm{dez} .2019$.

PASSO FUNDO. Prefeitura Municipal de Passo Fundo. Revisão do Plano Diretor. Diagnóstico Participativo. Volume I. 2018. Disponível em: http://www.pmpf.rs.gov.br/files/ minuta_produto_2_diagnostico_participativo.pdf. Consultado em: 19 maio 2019.

PASSO FUNDO. Prefeitura Municipal de Passo Fundo. Minuta produto 2: Diagnóstico Participativo. 2017. Disponível em: http://www.pmpf.rs.gov.br/files/minuta_produto_2 diagnostico_participativo.pdf. Consultado em: 21 maio 2019.

PASSO FUNDO. Prefeitura Municipal de Passo Fundo. Mapa Bairros. Disponível em: https://www.google.com/maps/d/u/0/embed?mid=1XnQwAMCQRtFJ3GDpDk7sFvn$232 c \& \mid l=-28.263282441102692 \% 2 C-52.42696485192869 \& z=13$. Consultado em: 18 maio 2019a.

PASSO FUNDO. Prefeitura Municipal de Passo Fundo. Revisão do Plano Diretor. Metodologia Participativa. Disponível em: http://www.pmpf.rs.gov.br/servicos/geral/ multimidia/revisao_pddi_etapa1_minuta_metodologia_paticipativa.pdf Consultado em: 19 maio $2019 \mathrm{~b}$.

QUAPÁ. Sobre o Quapá. Disponível em: http://quapa.fau.usp.br/. Consultado em: 20 maio 2019.

RODIGHERI, M.; GEHM, E.; BITENCOURT, L. As transformações espaciais do território do município de Passo Fundo - 1857 - 1992. In: Estudos de geografia regional: o urbano, o rural e o urbano na região de Passo Fundo. Passo Fundo: EDUPF, p. 69-99, 2004.

TEDESCO, J. C.; SANDER, R. Madeireiros, comerciantes e granjeiros: lógicas e contradições no processo de desenvolvimento socioeconômico de Passo Fundo (1900-1960). $2^{\mathrm{a}}$ ed. Passo Fundo: UPF, 2005

\section{Agradecimentos}

Ao Programa de Suporte à Pós-Graduação de Instituições de Ensino Superior (PROSUP) da CAPES (Coordenação de Aperfeiçoamento de Pessoal de Nível Superior) pela concessão da bolsa de estudos e ao Programa de Pós-graduação stricto sensu em Arquitetura e Urbanismo (PPGARQ) da IMED, Campus Passo Fundo/RS.
Laura Campagna Basso

IMED, Mestranda do Programa de Pós-Graduação em Arquitetura e Urbanismo, Escola Politécnica, IMED.

Rua Senador Pinheiro, 304, Centro, Passo Fundo, RS, Brasil.

https://orcid.org/0000-0003-2710-251X

lauracbasso@hotmail.com

\section{Lauro André Ribeiro}

IMED, Professor do Programa de Pós-Graduação em Arquitetura e Urbanismo, Escola Politécnica, IMED.

Rua Senador Pinheiro, 304, Centro, Passo Fundo, RS, Brasil. https://orcid.org/0000-0001-8640-3289

lauro.ribeiro@imed.edu.br

\section{Grace Tibério Cardoso}

IMED, Professor do Programa de Pós-Graduação em Arquitetura e Urbanismo, Escola Politécnica, IMED.

Rua Senador Pinheiro, 304, Centro, Passo Fundo, RS, Brasil. https://orcid.org/0000-0002-1779-4631

grace.cardoso@imed.edu.br

Notas do Editor:

Data de Submissão: 17/06/2019

Aprovação: 06/08/2020

Revisão: RMO 